\title{
Resource Optimization and Innovation of English Major Cultivation under the Background of Transitional Development
}

\author{
Wenjie Lin ${ }^{1, a}$, Yi Zhang ${ }^{2, b, *}$
}

1 Dalian Neusoft University of Information, Dalian, Liaoning, China

${ }^{2}$ Dalian Neusoft University of Information, Dalian, Liaoning, China

alinwenjie@neusoft.edu.cn, bzhangyi@neusoft.edu.cn

${ }^{*}$ Corresponding author: Lin Wenjie

Keywords: English Major, Resource Optimization, Cooperation between Chinese and Foreign Teachers, Extensive Courses, International Cooperative Talent Cultivation.

\begin{abstract}
The higher education of China is facing challenge from the new era and new development. It is necessary for college talent cultivation to find a creative reform way in order to meet the need of society, local areas and self-development instead of sticking to conventional mode and curriculum. Due to the large population and limited resources of China, colleges and the teaching units of all levels are urged to adjust their talent cultivating philosophies, set up a global view and accommodate with the developing tendency of economic globalization, keeping updating with time. For the purpose of optimizing resource allocation, colleges not only need to integrate all resources at hand but also have to extend cooperation partnership home and abroad and set opening education as their goals.
\end{abstract}

\section{转型发展背景下英语专业人才培养资源优化与创新 \\ 林文杰1, a , 张翼2,b, \\ 1大连东软信息学院, 沙河口区, 大连, 辽宁, 中国 \\ ${ }^{2}$ 大连东软信息学院, 沙河口区, 大连, 辽宁, 中国 \\ aemail: linwenjie@neusoft.edu.cn, bemail: zhangyi@neusoft.edu.cn \\ “通讯作者:林文杰}

关键词：英语专业; 资源优化; 中教与外教合作；拓展课程; 国际合作办学

中文摘要: 我国高等教育正经历着新时期、新发展的考验。高校人才培养需要不断创新, 不 拘于传统的模式和课程体系, 摸索适合社会需要、地区和自身发展的改革道路。在我国人口 众多, 资源有限的条件下, 高校和各级教学单位需要不断调整办学思想, 与时俱进, 树立全 球发展意识, 放宽眼界, 以适应经济全球化的发展趋势。在资源配置上做好最大优化, 不但 要充分整合和利用好现有资源, 还要不断发展和拓宽国内外合作领域, 树立开放式办学目标。

\section{1. 引言}

21 世纪是一个国际化知识经济年代, 国际化的就业市场所带来的挑战决定了高校英语专 业所培养的人才应是具有扎实的基本功、宽广的知识面、一定的相关专业知识、能力强和素 质高的 “宽”适应性人才。也就是在打好扎实的英语语言基本功和牢固英语专业知识的前提 
下，拓宽人文知识和科技知识，掌握与毕业后所从事的工作有关的专业基础知识，注重培养 获取知识的能力、实践能力和创新能力。相对于原有的英语专业人才培养目标, 新的时代特 征对于英语专业人才的需求突出体现在了国际化、综合化和能力化几个特征方面。与不断更 新、提高的人才需求相比, 现有的高校英语专业人才培养主要存在的问题表现在:

1) 学生的专业能力 “有而不精”。高校教学大多把学生整体视为统一对象, 对于学生的个 体差异重视不足，因而难以很好达到因材施教和个性化培养，培养的学生缺乏竞争力。

2) 学生缺乏国际化视野。我国高校的英语专业教学以语言技能训练为主, 学生语言学习环 境单一化明显, 教学重点局限于语言教学而忽视了培养学生的国际化视野和宽口径知识。

3) 一体化教学有待进一步加强。现有的课程体系下, 英语专业课程设置以综合技能课程和 听说读写译分项技能课程为主, 语言技能强化训练的同时而忽视了对学生综合能力和学 习实践能力的培养, 因此在人才培养方面仍需大胆创新。

4) 中教与外教教学割裂。虽然高校英语专业都聘用外籍教师担任部分课程教学, 但外籍教 师在学科中发挥的作用不明显, 外教授课科目相对单一固定, 中教与外教师资交流和合 作研究十分缺乏，外教资源没有得到很好的利用。

\section{2. 英语专业人才培养资源优化与创新举措}

为使英语专业学生在专业知识上更扎实、更出色, 拓宽视野和发展潜力, 培养出更多能 力强、素质高、具有国际视野的毕业生, 提高其毕业竞争力, 我们在必修与选修课之外开展 “拓展课程” , 其目的是通过对中教与外教师资、学生、课程等资源进一步优化配置, 提高 国际化和实用化办学, 进一步增强因材施教和多样化教学力度, 以提升人才培养质量。课程 由中、外教合作建设, 是对现有英语专业课程设置主体的有益补充。另外, 我们也大力拓展 国际合作项目, 为更多学生提供在校期间短期到国外学习和实习机会, 增加与国外校际间的 互派学生交流, 使学生开拓国际化眼界, 增加校内外实践经历, 提高综合素质和就业竞争力。

结合我校正在实施的CDIO国际工程教育理念及OBE (Outcome-based Education) 教学改 革, 我们以构思（Conceive）、设计（Design）、实现（Implement）和运作（Operate）四个 关键词为核心, 让学生以主动的、实践的和课程之间相互关联的方式进行学习。为此, 我们 对资源进行了优化与创新。作为英语专业在教学一体化和人才培养资源优化方面的新尝试,

“拓展课程” 在实施过程中, 主要从项目的内容与安排、教学师资、和学生选拔与管理几个 方面解决一些关键问题。主要表现在如下方面:

\section{1 师资配备}

拓展课程的师资由中教和外教组成, 中教侧重于项目方案设计和教学管理, 外教侧重于 授课和学生指导, 教学内容由中、外教合作研发。在大学教学任务安排中, 一般来说外教主 要担当口语课独立的教学任务, 工作十分独立, 与中教团队缺乏交流, 更谈不上合作研究和 开发课程。但我们通过对外教聘任和教学管理的改革, 将外教和中教师资进一步融合起来, 通过具体工作如课程建设、学生指导等, 更好的发挥外籍教师在整个专业人才培养中的作用。 要做到这一点, 主要困难是外教师资的人力特点和管理方式与我们中教大不一样, 他们在中 国的工作目标主要是短期性为主, 而参与到学生指导和拓展课教学等工作需要投入课堂教学 外更多的而时间和精力，沟通和合作机制也需要有明确的方案和组织方法。

我们解决这个问题的主要措施有：首先，改革外教管理机制，建立外教工作激励机制， 适当减免常规教学授课学时, 折合非常规教学工作量; 其次, 中教发挥主导作用, 设计拓展 教学项目和管理方案, 设定明确的教学目标, 在此基础上外教对计划进行进一步丰富和完善, 并与中教合作设计教学内容, 担当教学和学生指导工作。外教在教学实施和学生指导方面发 挥更加积极的作用, 而中教则在教学管理、目标设定和组织实施过程中起到关键的作用。 


\section{2 教学形式}

拓展课程教学形式多样, 注重科目间的关联和一体化教学, 重视学生能力的培养和潜力 的挖掘, 不局限于某个教材, 而是根据职业面向能力要求和专业培养目标设计动态教学内容 和教学活动, 培养学生的专业和综合能力。以下是拓展课程设计思想和组织方式的具体实例:

为培养学生的阅读习惯和思维能力, 提高学生对各领域知识的了解, 我们选拔学生开设 了网络新闻阅读拓展课程。以每周的网络阅读为主要教学形式, 由中教和外教商定选材, 取 材于国内外主要的新闻网站和期刊, 外教主要授课国外新闻网站阅读, 中教主要授课国内新 闻网站阅读, 帮助学生养成每日阅读新闻的习惯。教师指导学生熟悉新闻网站的特点和阅读 技巧, 选材和汶览要点, 介绍文化和事件背景, 总结重要事件的来龙去脉, 就争议问题进行 讨论和组织辩论。阅读内容注重时文性和题材的广泛多样性, 使学生学习鲜活的语言和了解 世界的发展。中教与外教的讲授和指导环节更能够帮助学生积极思考, 交流总结, 有利于学 生养成良好的网络新闻阅读的习惯。同时, 我们也要求教师给学生布置一定的写作练笔的任 务, 选择合适的主题, 每周撰写阅读笔记或议论文, 结合小组讨论和互阅环节, 再进行修改 和完善, 教师也要对学生的写作给予定期的指导和及时的总结。

此外，我们也自主研发了拓展课程网站，内容包括分题材的新闻阅读、分题材的新闻听 力、有相关文化和事件背景介绍、归类新闻词汇、热点评议, 鼓励学生网络交流和写作, 并 设置答疑区供师生交流互动。网站由教师指导学生主要进行构建和管理。这里我们将学生的 阅读能力、写作能力、口语能力、听力能力的培养有效的整合, 各项技能融会贯通, 相辅相 成, 同时更注重学生的学习态度和习惯的养成, 锻炼思维、沟通交流、团队合作等综合全面 的能力, 发展个人能力、职业能力和态度。

\section{3 国际合作办学}

国际合作办学是语言专业人才培养的重要组成, 有利于培养具有全球意识和国际视野的 新型人才。走国际化办学道路, 培养复合型语言专业人才, 是新时期外语专业学科发展的重 要途径。为拓宽语言专业学生的国际化视野, 放宽眼界, 我们采用灵活多样的方式开展中外 合作办学, 力争使在校三年级的本科学生三分一直都有机会去国外交流学习或实习, 时间有 一年或半年或三个月不等, 并承认其在国外大学所获得的学分, 同时也有少数项目可以满足 学生获得双学位的愿望。这样不仅可以使学生在更为便利的语言环境下更好地掌握英语, 还 能够零距离地感受英语国家的文化和社会环境。在选择国外学校课程方面, 我们尽量为学生 选择应用性的专业方向类或相关专业类课程, 加大专业方向课程的教学力度, 从而使学生在 提高语言技能的同时，拓宽相关专业知识，适应现代社会的人才标准。

另一方面, 我们也积极吸引国外大学向我校派遣教师和学生进行同课堂学习和交流。特 别是开展 “全球化课堂” 合作项目, 邀请国外大学教授带队学生10-15人到我校短期交流, 双 方等数量学生一起上课2-3周, 食宿安排在一起, 课堂由国外大学访问教授主讲, 课后活动由 中国教师和学生一起组织, 包括参观和游览、互助语言学习、文化交流等。这样为我们的学 生在中国也提供了一个国际化的课堂和校园环境, 能够近距离地与国外大学老师和学生交流, 近距离地一起校园生活。开展灵活多样的国际化办学, 将极大有利于学生树立全球意识, 增 强跨文化交流能力和自主创新能力, 使之成为具有国际视野并能参与全球性竞争与合作的复 合型、应用型的高素质外语专业人才。

\section{3 英语专业人才培养资源优化与创新的特色及创新之处}

转型发展背景下英语专业人才培养资源优化与创新是对传统英语新闻教学模式的改革, 也是英语专业整体教学模式改革的初步探索, 带有鲜明的特色和创新性, 主要表现在:

符合国际化人才培养模式要求。CDIO基于工程过程的教学理念, 更加注重理论知识和实 践相结合, 强调对学生知识运用能力的培养, 符合现代化就业环境对人才的需求。“拓展课 
程” 教学模式的探索就是在这一先进的教学理念指导下进行研究的, 其核心在于培养学生在 教师指导下开展有重点的自我学习和实践, 符合国际化人才培养模式的要求。

强调学科间的相互支撑和联系。抓住单一学科教学重点的同时兼顾各个科目之间的相互 联系有利于从知识储备整体上对学生进行培养。以媒体新闻为载体, 使学生广泛接触各个方 面的知识, 有利于一体化教学体系的构建。

优化人才培养配置。“拓展课程” 是面向有资质的英语专业学生开设, 在课程内容上凸 现了因材施教原则, 有别于一刀切的笼统教学模式, 能够从更优的层面上改进人才培养模式。

体现了现代化教学特色。网络的出现和多媒体计算机的使用使现代化教学变得更加直观 和更具有趣味性。而课程网站的架设, 使课程从课堂延伸到了网络, 从而实现了教学的立体 建设, 体现了这一时代的教学特色。

\section{4 结语}

我国的高等教育正经历着新时期、新发展的考验。社会的新时期发展对语言专业的培养 计划提出了新的要求, 对传统的课程设置和教学内容都提出了挑战。语言专业需要适时转变 教育观念, 探索人才培养的多种模式, 改革课程设置和教学内容, 坚持复合型、应用型人才 培养。同时, 加速国际化进程, 吸纳国内外优质教育资源, 不断发展和拓宽国内外合作领域, 在资源的配置上做到充分利用和最大优化。只有加快教育教学改革和创新的步伐, 树立开放 式办学的目标，高校语言类专业才能得到新的发展，适应经济全球化的发展趋势。

\section{References}

[1] Gao Fengxia, Exploration and Practice on talent cultivation mode of English major, Journal of Hubei Correspondence University, vol.25, pp. 127-128, 2012.

[2] Guo Juanjuan, A research on cultivation mode of English professional talents in independent colleges, Journal of Changchun University, vol.13, pp. 160-161, 2014.

[3] Hu Wenzhong, The strengths and weaknesses of China's foreign language education in the past 60 years, Foreign Language Teaching and Research, vol.41, pp.163-169, 2009.

[4] Shi Yunlong, On talent cultivation of English major under the new situation, JiangSu GaoJiao, vol. 1, pp.108-110, 2007.

[5] Shun Changshun and Li Xiaoyu, A research on cultivation mode of English professional talents in independent colleges, Journal of Changchun University, vol.23, pp. 997-1000, 2013.

[6] Wang Xianzhi, Tentative construction of interdisciplinary English major schemes in universities of science and engineering, Journal of Shijiazhuang Railway Institute (Social Science), vol.3, pp. 111-114, 2009.

[7] Xiao Youqun, Zeng Xiaorong and Xiaol Lan, Cultivation mode for English majors with compound expertise based on Multiple Intelligence Theory: Construction and Practice, Foreign Language and Literature, vol.31, pp. 138-142, 2015.

[8] Yang Wei and He Xiaolin, A Research on application-oriented talent cultivation mode of English major under the background of transitional development, Chinses Vocational and Technical Education, vol.4, pp.38-41, 2016.

[9] Ye Xingguo, On innovation of training modes of English major, Journal of University for Shanghai Science and Technology, vol.33, pp.297-302, 2011. 
[10]Zhao xinhong, The problems and countermeasures of talent cultivation mode of English major under the background of transitional development, Journal of Kaifeng Institution of Education, vol.37, pp.33-34, 2017. 